\title{
Exploring the happiness and sense of purpose associated with older peoples' activities using ecological momentary analysis: an observational study
}

Karen Elizabeth Hancock ( $\nabla$ k.hancock@lboro.ac.uk)

Loughborough University https://orcid.org/0000-0002-8453-2623

Paul Downward

Loughborough University

Lauren Sherar

Loughborough University

\section{Research}

Keywords:

Posted Date: May 18th, 2020

DOI: https://doi.org/10.21203/rs.3.rs-29145/v1

License: (9) (1) This work is licensed under a Creative Commons Attribution 4.0 International License. Read Full License 


\section{Abstract}

Background

Older people have more leisure time, but many are physically inactive. Momentary feelings of pleasure or happiness and sense of purpose can be sources of intrinsic motivation. This study's objective was to investigate how the type (sedentary, active) and context (social and environmental) of older peoples' activities relate to momentary feelings of happiness and purpose.

Methods

Details of activities, contexts and feelings of retired or semi-retired adults ( $n=67$, aged 50-78y) were captured over 7 days using ecological momentary assessment (EMA) via a smart phone app. Participants were prompted on their smart phone six times at random per day, resulting in 2,065 valid prompts. They wore an Actigraph accelerometer on the waist for 7 days to measure physical activity. Happiness and sense of purpose outcome variables were regressed on activities, context and potential confounding variables (e.g. age, gender, physical activity). Regression standard errors were clustered on participants to account for the hierarchically structured data. Interactions between activities and contexts were explored.

Results

Participants were highly active: $98.5 \%$ met physical activity guidelines. Sedentary activities were negatively associated with sense of purpose, especially when indoors. Social sedentary activities (e.g. visiting friends and family) were, however, positively associated with feelings of happiness. Active, social outdoor activities were positively associated with both outcomes. Less sedentary participants experienced higher happiness and sense of purpose during all their activities: each 1 percentage point increase in percentage time sedentary was associated with a reduction of 2.78-points on the happiness scale and 3.34 on the purpose scale ( $p$ $<0.05)$.

Conclusions

Context is important for happiness and purpose, with social and outdoor activities likely to have the widest appeal for older adults. The study needs to be replicated in larger and more representative samples of older adults.

\section{Background And Rationale}

The benefits of physical activity for slowing the ageing process and improving quality and length of life are well-known (Bangsbo et al., 2019), yet $>25 \%$ of adults 55-64y in England report fewer than 30 minutes per week at health-improving moderate-vigorous intensity. The percentage inactive rises to almost 70\% for those aged 85+ (Sport England, 2019).

Sense of purpose and pleasure are sources of intrinsic motivation identified in self-determination theory (Ryan and Deci, 2001), which underpins many health-related behaviour change interventions (Patrick and Williams, 2012), and could be leveraged to promote physical activity among older people (Cabrita et al., 2017) who try to balance feelings of pleasure- (i.e. happiness - and purpose) from moment to moment in everyday life (Dolan, 2014). Understanding how older peoples' activities relate to momentary feelings of happiness and/or purpose would help to inform the design of effective interventions and policies to increase physical activity and reduce sedentary behaviour among older people, which is a public health priority (Public Health England, 2014).

Previous studies of older peoples' activities and their relationship to experiential feelings use retrospective evaluations (Oerlemans, Bakker and Veenhoven, 2011; Kavčič and Avsec, 2018; Stone et al., 2018). A recent study of older adults sampled using the American Time-Use Survey (ATUS) found Dactive leisure (e.g. sports, exercise and recreation) was associated with greater

'happiness' and 'meaningfulness' when compared with passive (sedentary) leisure (e.g. screen time) (Yamashita, Bardo and Liu, 2018). However, this study did not consider activities' social and environmental contexts, which are important among older people (Finlay et al., 2015; Boulton, Horne and Todd, 2018). Furthermore, activities were classified as active or passive retrospectively by the researchers, which risked misclassifications. Moreover, memories of feelings experienced yesterday - as collected by the ATUS - are less reliable than immediate recall, particularly for older adults (Galenkamp et al., 2016), who may be experiencing decline in shortterm memory (Verhaeghen, 2013). 
A more accurate method of capturing behaviour, feelings and contexts simultaneously is via prompted, frequent, real-time selfreports known as ecological momentary assessments (EMA) (Shiffman, Stone and Hufford, 2008). A study using smartphonedelivered EMA over 30 days in a small sample $(n=10)$ of older adults $(65-83 y)$, found that social, outdoor leisure activities were associated with higher experiential pleasure than non-leisure activities performed alone or indoors (Cabrita et al., 2017). Experiential feelings of purpose were not considered in this study.

The objective of this study, therefore, was to investigate how the type (sedentary, active), social (alone or with others) and environmental (indoors or outdoors) contexts of activities relate to momentary feelings of happiness and purpose assessed using EMA methods in a sample of retired or semi-retired, community-living older adults.

\section{Methods}

\section{Study Design, Participants And Setting}

A cross-sectional observational design was adopted. Participants were recruited via responses to messages posted on social media groups (e.g. Facebook sports club groups), forums (e.g. London School of Economics Alumni) and personal contacts. Participants were eligible if $\geq 50$ years, fully or semi-retired, owned a smart-phone, and able to attend an enrolment meeting in London or Loughborough, East Midlands (UK). Seventy-three adults met the inclusion criteria and consented to take part. Recruitment spanned February to December 2019. During their enrolment meeting, eligible participants provided informed consent, were familiarised with study procedures and equipment, assigned an initialised Actigraph activity monitor, shown how to download and login to the EMA app and asked to complete a survey.

\section{Measurements and procedures}

\section{Ecological Momentary Assessment}

Details of activities, contexts and feelings were captured using EMA (Shiffman, Stone and Hufford, 2008). Several studies have demonstrated the feasibility, acceptability, reliability and validity of smartphone-based EMA to measure behaviours and feelings in a variety of older populations (Maher, Rebar and Dunton, 2018; Paolillo et al., 2018; Liu and Lou, 2018). Ethica software (www.ethicadata.com) was selected because it had both Android and IOS versions, making it compatible with most mobile phones. The EMA protocol was piloted in six smartphone users aged $50+$ and modifications made.

At the initial meeting participants completed a survey through the Ethica app which asked about age, gender, ethnicity, religion, selfassessed health, highest educational level achieved, whether living alone, whether working part-time or not, number of adults in household, and overall life satisfaction and worthwhileness of life, all of which have been previously identified as confounding factors in analyses of subjective wellbeing (Dolan, Kudrna and Stone, 2017), or associated with choice of leisure-time activities (Galenkamp et al., 2016). Principal sources for question wordings included the Office for National Statistics harmonised wordings for the 2011 Census and the Taking Part Survey questions (Ipsos MORI, 2018)

Over the seven days of monitoring, participants received six prompts at random within 150-minute windows between 06:30 and 21:30 to complete 6 questions about their main activity in the last hour and their feelings of happiness and sense of purpose during that activity. They were instructed to answer prompts immediately but only when safe and convenient. Participants were asked: What was your main activity in the last hour? (21 activities, grouped into six higher-level categories (physical, mental, social, recreational, travel and resting), similar to those used in previous studies of older peoples' activities (Chang, Wray and Lin, 2014); Galenkamp et al., 2016; Yamashita, Bardo and Liu, 2018)). They were then asked to rate their happiness and sense of purpose on a visual analogue scale by moving a slider from the default setting of 5 to a number between 0 (not at all) and 10 (totally/wholly) (Office for National Statistics, 2015; Cabrita et.al., 2017). Participants were then asked: What was your posture while carrying out this activity? (Standing/Sitting/Lying Down/Moving about). Were you indoors or outdoors while doing it? (Indoors at home/ Indoors another venue/In a vehicle/ Outdoors/Mix of the above). Who were you doing it with? (Alone/With a pet/With people I don't know/With people I met through this activity/With friends/family/With a service provider (e.g. doctor; shop assistant). 


\section{Accelerometry}

Participants were asked to wear an Actigraph accelerometer, either GT3x or wGT3X- BT (Actigraph, 2013) over the right hip using an elasticated waist band during waking hours for seven consecutive days. These devices have been identified as having acceptable validity and reliability in older adults (Copeland and Esliger, 2009). Data were collected at a sampling rate of $100 \mathrm{~Hz}$ and downloaded in epochs of 60 seconds for analysis using Actilife software. Raw Actigraph data files were reprocessed to derive outcome variables, using custom data reduction software (KineSoft, V.3.3.67, Loughborough, UK). Non-wear time was defined as $\geq 60$ minutes of consecutive zero counts, allowing for 2 minutes of non-zero interruptions (Tay, Chan and Diener, 2014). Participants' accelerometer data was considered valid if they had $\geq 5$ days with $\geq 10$ hours of valid accelerometer wear (Pruitt et al., 2008). Vertical axis intensity cut-points derived for use in older participants were adopted (Copeland and Esliger, 2009).

\section{Statistical Methods}

The unit of analysis is a single response to an EMA prompt. Happiness and purpose outcome measures were regressed on activities undertaken, controlling for confounding influences from the social and environmental context (e.g. where they took place), accelerometer assessed physical activity/time spent sedentary, and participant characteristics. Given the use of multiple regression methods, a key consideration governing sample size was degrees of freedom. Using a two-tailed test and $95 \%$ confidence level, assuming 20 independent variables, a sample size of 1,302 responses was sufficient to detect a very small effect size of 0.01 (Faul, F., Erdfelder, E., Lang, A.-G. \& Buchner, 2007). To account for the hierarchically-structured the data, the errors of the regressions were clustered on individuals. Given the number of independent variables that could potentially be included in the regressions, multicollinearity was likely. To preserve degrees of freedom, a pragmatic approach was adopted. Accordingly, backwards elimination was used to derive parsimonious estimates, and further independent variables were removed where variance inflation factors exceeded 10, which eliminated most of the confounding variables except for accelerometer assessed sedentary time. All analyses were conducted using Stata version 14.2 (StataCorp, 2018) and statistical significance was set at $p<0.05$.

\section{Results}

Six participants were removed as they did not meet the criteria for valid accelerometer data. Data on 67 (92\%) participants were retained for analysis. The maximum number of responses per participant was 42 (i.e. 6 per day). Owing to missing data, 560 EMA responses were removed, leaving 2,065 from 67 participants - an average of 4.4 per participant per day: a response rate of $73.3 \%$. Sample characteristics are presented in Table 1. Participants ranged from 50-78 years of age, were predominantly white British, had at least degree-level education, mainly resident in London, in good or better self-assessed health, and all except one met the current physical activity guidelines ( $\geq 150$ minutes of MVPA weekly (Public Health England, 2014). Mean values for feelings of momentary happiness and sense of purpose were in line with those found for measures of wellbeing in other surveys using the same scale, e.g. Office for National Statistics, (2020). 


\begin{tabular}{|c|c|c|c|}
\hline \multicolumn{2}{|l|}{ Characteristic } & Frequency/Mean* & $\%\left(s d^{*}\right)$ \\
\hline \multicolumn{2}{|l|}{ Age $(y)$} & $64.1^{\star}$ & $5.92^{*}$ \\
\hline \multirow[t]{2}{*}{ Gender } & Male & 29 & 43.3 \\
\hline & Female & 38 & 56.7 \\
\hline \multirow[t]{2}{*}{ Ethnicity } & White British & 63 & 94.1 \\
\hline & Other & 4 & 5.9 \\
\hline \multirow[t]{2}{*}{ Relationship status } & Living in a couple & 44 & 65.7 \\
\hline & Living alone & 23 & 34.3 \\
\hline \multirow[t]{2}{*}{ Highest educational level } & Degree or above & 48 & 71.0 \\
\hline & No degree & 19 & 29.0 \\
\hline \multirow[t]{2}{*}{ Location } & London zones 1-6 & 52 & 77.6 \\
\hline & Not London & 17 & 22.4 \\
\hline \multirow[t]{2}{*}{ Self-Assessed Health } & 'Very Good' or 'Good' & 65 & 97.0 \\
\hline & 'Fair' or 'Poor' & 2 & 3.0 \\
\hline \multicolumn{2}{|l|}{ Met MVPA guidelines ${ }^{1}$} & 66 & 98.6 \\
\hline \multicolumn{2}{|l|}{$\%$ of wear time spent in MVPA } & $9.9 *$ & $5.7^{*}$ \\
\hline \multicolumn{2}{|l|}{$\%$ of wear time spent sedentary } & $62.5^{\star}$ & $7.9 *$ \\
\hline \multicolumn{2}{|l|}{ Happiness score } & 7.2 & $1.65^{\star}$ \\
\hline \multicolumn{2}{|l|}{ Sense of purpose score } & 7.3 & $1.73^{\star}$ \\
\hline \multicolumn{2}{|l|}{$\mathrm{N}$} & 67 & \\
\hline \multicolumn{4}{|c|}{$\begin{array}{l}{ }^{1} \text { MVPA = moderate-to-vigorous physical activity guideline } \geq 150 \text { mins MVPA per week } \\
\text { sd = standard deviation }\end{array}$} \\
\hline
\end{tabular}

[ Table 1 here]

Table 2 shows the categorisations and frequencies of participation in different activities. The most reported activity was physical with moderate intensity sport/exercise being the most common (22\%). Mental activities were the next most common, with screen time being the most frequent (9.5\%). For the regression analyses, the 22 individual activities were reduced to 13 by combining similar 
activities (e.g. moderate and vigorous sport/exercise both count towards meeting the current physical activity guidelines) and merging low-frequency activities into larger categories. Light sport/exercise was retained as a separate category because it does not count towards the recommended 150 minutes a week of physical activity. 
Table 2

Categories and frequencies of activities

\begin{tabular}{|c|c|c|c|c|c|c|c|c|}
\hline & Frequency & $(\%)$ & & Frequency & $(\%)$ & $\begin{array}{l}\text { Final analytical } \\
\text { categories (13) }\end{array}$ & Frequency & $(\%)$ \\
\hline \multirow[t]{6}{*}{$\begin{array}{l}\text { Physical } \\
\text { activities }\end{array}$} & \multirow[t]{6}{*}{744} & 36.0 & $\begin{array}{l}\text { Light sport or } \\
\text { exercise }\end{array}$ & 118 & 5.7 & $\begin{array}{l}\text { Light sport or } \\
\text { exercise }\end{array}$ & 118 & 5.7 \\
\hline & & & $\begin{array}{l}\text { Moderate sport or } \\
\text { exercise }\end{array}$ & 363 & 17.6 & \multirow{2}{*}{$\begin{array}{l}\text { Moderate or } \\
\text { vigorous sport or } \\
\text { exercise }\end{array}$} & \multirow[t]{2}{*}{458} & 22.2 \\
\hline & & & $\begin{array}{l}\text { Vigorous sport or } \\
\text { exercise }\end{array}$ & 95 & 4.6 & & & \\
\hline & & & Domestic tasks & 71 & 3.4 & \multirow{2}{*}{$\begin{array}{l}\text { Domestic tasks or } \\
\text { errands }\end{array}$} & \multirow[t]{2}{*}{123} & 5.9 \\
\hline & & & $\begin{array}{l}\text { Shopping, errands } \\
\text { or queuing }\end{array}$ & 52 & 2.5 & & & \\
\hline & & & DIY/Gardening & 45 & 2.2 & DIY/Gardening & 45 & 2.2 \\
\hline \multirow{6}{*}{$\begin{array}{l}\text { Mental } \\
\text { Activities }\end{array}$} & \multirow[t]{6}{*}{432} & 20.9 & Screen time & 196 & 9.5 & \multirow{2}{*}{$\begin{array}{l}\text { Mentally passive } \\
\text { activities }\end{array}$} & \multirow[t]{2}{*}{271} & 13.1 \\
\hline & & & $\begin{array}{l}\text { Reading/listening } \\
\text { for pleasure }\end{array}$ & 75 & 3.6 & & & \\
\hline & & & $\begin{array}{l}\text { Studying/learning a } \\
\text { new skill }\end{array}$ & 24 & 1.2 & \multirow[t]{4}{*}{$\begin{array}{l}\text { Mentally active } \\
\text { activities }\end{array}$} & \multirow[t]{4}{*}{161} & 7.8 \\
\hline & & & Games or puzzles & 16 & 0.8 & & & \\
\hline & & & $\begin{array}{l}\text { Planning/organising } \\
\text { or admin tasks }\end{array}$ & 115 & 5.5 & & & \\
\hline & & & $\begin{array}{l}\text { Praying or } \\
\text { meditating }\end{array}$ & 6 & 0.3 & & & \\
\hline \multirow[t]{4}{*}{$\begin{array}{l}\text { Social } \\
\text { Activities }\end{array}$} & \multirow[t]{4}{*}{299} & 14.5 & $\begin{array}{l}\text { Visiting/entertaining } \\
\text { friends or family }\end{array}$ & 135 & 6.5 & $\begin{array}{l}\text { Visiting/entertaining } \\
\text { friends or family }\end{array}$ & 135 & 6.5 \\
\hline & & & $\begin{array}{l}\text { Going to pub, club, } \\
\text { café or restaurant }\end{array}$ & 95 & 4.6 & $\begin{array}{l}\text { Going to pub, club, } \\
\text { café or restaurant }\end{array}$ & 95 & 4.6 \\
\hline & & & Volunteering & 24 & 1.2 & \multirow{2}{*}{$\begin{array}{l}\text { Volunteering or } \\
\text { caring for someone }\end{array}$} & \multirow[t]{2}{*}{69} & 3.4 \\
\hline & & & $\begin{array}{l}\text { Caring for or helping } \\
\text { someone }\end{array}$ & 45 & 2.2 & & & \\
\hline \multirow[t]{3}{*}{$\begin{array}{l}\text { Recreational } \\
\text { activities }\end{array}$} & \multirow[t]{3}{*}{109} & 5.3 & $\begin{array}{l}\text { Attending concert, } \\
\text { film, theatre or } \\
\text { sporting event }\end{array}$ & 40 & 2.0 & \multirow{2}{*}{$\begin{array}{l}\text { Attending cultural or } \\
\text { sporting event or } \\
\text { visiting a cultural } \\
\text { attraction }\end{array}$} & \multirow[t]{2}{*}{53} & 2.6 \\
\hline & & & $\begin{array}{l}\text { Visiting museum, } \\
\text { gallery or other } \\
\text { cultural attraction }\end{array}$ & 13 & 0.6 & & & \\
\hline & & & $\begin{array}{l}\text { Creative hobby (e.g. } \\
\text { woodwork, baking, } \\
\text { making music etc) }\end{array}$ & 56 & 2.7 & Creative hobby & 56 & 2.7 \\
\hline Travel & 171 & 8.3 & Travel & 171 & 8.3 & Travel & 171 & 8.3 \\
\hline Resting (s) & 310 & 15.0 & Resting & 310 & 15.0 & Resting & 310 & 15.0 \\
\hline $\mathrm{n}$ & 2,065 & 100.0 & & 2,065 & 100.0 & & 2,065 & 100.0 \\
\hline
\end{tabular}

[Table 2 here] 
Sport or exercise at moderate-vigorous intensity was not significantly associated with either happiness or sense of purpose when compared with mentally passive activities, such as screen time (Table 3). Sport or exercise at light intensity had a positive association with sense of purpose but volunteering or caring for someone had the largest association with sense of purpose of any of the 13 activities. Activities that had the strongest association with momentary happiness were social (e.g. visiting or entertaining friends or family, and going out to a pub, club or restaurant), or recreational (e.g. attending a theatre or other cultural attraction).

Table 3

Predictors of older adults' momentary happiness and purpose

\begin{tabular}{|c|c|c|c|c|}
\hline \multirow[t]{2}{*}{ Predictors } & \multicolumn{2}{|c|}{ Happiness } & \multicolumn{2}{|c|}{ Sense of Purpose } \\
\hline & Beta & $95 \% \mathrm{Cl}$ & Beta & $95 \% \mathrm{Cl}$ \\
\hline \multicolumn{5}{|l|}{ Participant characteristics } \\
\hline Percentage of wear time sedentary & $-2.802^{\star}$ & -5.33 to -0.266 & -3.2568 & -5.896 to -0.596 \\
\hline \multicolumn{5}{|c|}{ Activities (Base $=$ Mentally Passive Activities) } \\
\hline Light sport/ex & 0.257 & -0.233 to 0.804 & $0.662^{\star \star}$ & 0.169 to 1.156 \\
\hline Mod-vigorous sport/ex & -0.409 & -0.854 to 0.028 & 0.398 & -0.624 to 0.858 \\
\hline Domestic tasks & 0.003 & -0.403 to 0.540 & $0.681 * \star$ & 0.212 to 1.150 \\
\hline DIY/Gardening & 0.404 & -0.172 to 1.110 & 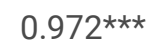 & 0.426 TO 1.518 \\
\hline Visiting/entertaining friends or family & $0.741^{\star \star}$ & 0.233 to 1.200 & $0.707^{*}$ & 0.136 to 1.278 \\
\hline Going to pub, club, café or restaurant & $0.658^{* *}$ & 0.171 to 1.129 & 0.398 & -0.145 to 0.940 \\
\hline Volunteering/caring for someone & 0.498 & -0.158 to 1.1 .41 & $1.376^{\star \star \star}$ & 0.760 to 1.991 \\
\hline Mentally active & -0.339 & -0.789 to 0.124 & $0.660 * \star$ & 0.178 to 1.1 .43 \\
\hline Concert, film, theatre, museum etc & $0.995^{\star *}$ & 0.302 to 1.671 & $0.807^{*}$ & 0.814 to 1.532 \\
\hline Creative hobby & $0.888^{\star \star}$ & 0.340 to 1.437 & 1.151 *** & 0.602 to 1.700 \\
\hline Resting & -0.446 & -0.936 to 0.019 & 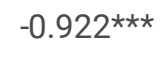 & -1.452 to -0.392 \\
\hline Travelling & $-0.852^{\star \star}$ & -1.338 to -0.270 & -0.134 & -0.716 to 0.447 \\
\hline \multicolumn{5}{|l|}{ Context variables } \\
\hline Social & $0.452^{\star *}$ & 0.198 to 0.705 & & \\
\hline Weekend & $0.253^{\star *}$ & 0.033 to 0.449 & & \\
\hline Outdoors & $0.798 * \star \star$ & 0.428 to 0.945 & $0.456^{\star}$ & 0.197 to 0.716 \\
\hline Observations & 2,065 & & 2,065 & \\
\hline Adjusted R-squared & 0.196 & & 0.179 & \\
\hline Model degrees of freedom & 17 & & 14 & \\
\hline \multicolumn{5}{|l|}{${ }^{*} p<0.05, * * p<0.01, * * x p<0.001$} \\
\hline Constant suppressed for space reasons & & & & \\
\hline
\end{tabular}

[Table 3 here]

Given the significance of context variables for happiness and purpose (Table 3), coupled with literature showing that being with others (i.e. social) and/or outdoors improved happiness among older people (Cabrita et al., 2017; Lam and García-Román, 2019; Sharifian and Grühn, 2019), the interaction between each of the activities and dichotomous variables for whether activities were active/sedentary; social/solo; and outdoors/indoors - as reported by participants - were explored. (Table 4). The regression shows that for many activities, context is important: social activities for example were positively associated with both outcomes compared 
to solo activities - with the exception of volunteering. In general, sedentary activities were negatively associated with both outcomes, unless they were social sedentary activities (e.g. visiting friends and family). Of the active recreational activities, those that were social and outdoors had the largest positive association with both outcomes. Less sedentary participants were more likely to experience higher feelings of happiness and sense of purpose during any recreational activity. 
Table 4

Active/Sedentary activities interacted with social and environmental context predicting older adults' momentary happiness and sense of purpose

\begin{tabular}{|c|c|c|c|c|}
\hline \multirow[t]{2}{*}{ Predictors } & \multicolumn{2}{|c|}{ Happiness } & \multicolumn{2}{|c|}{ Purpose } \\
\hline & Beta & $95 \% \mathrm{Cl}$ & Beta & $95 \% \mathrm{Cl}$ \\
\hline \multicolumn{5}{|l|}{ Participant characteristics } \\
\hline Percentage of wear time sedentary & -2.779 & -5.300 to -0.258 & -3.342 & -5.898 to -0.787 \\
\hline \multicolumn{5}{|c|}{$\begin{array}{l}\text { Activities interacted with Active/Sedentary, social and environmental context: base = Mentally Passive Activities, Active, Solo, } \\
\text { Outdoors }\end{array}$} \\
\hline \multicolumn{5}{|l|}{ Light Sport or Exercise } \\
\hline Active, Social, Outdoors & 1.025 & 0.122 to 1.923 & & \\
\hline Sedentary, Social, Indoors & 1.732 & 0.116 to 3.349 & & \\
\hline Sedentary, Social, Outdoors & -1.022 & -1.896 to -0.148 & & \\
\hline \multicolumn{5}{|l|}{ Moderate-Vigorous Sport or Exercise } \\
\hline Sedentary, Solo, Indoors & -1.411 & -2.773 to -.0490 & & \\
\hline \multicolumn{5}{|l|}{ Domestic tasks/errands } \\
\hline Active, Social, Outdoors & 1.409 & 0.389 to 2.4289 & 1.542 & 0.344 to 2.742 \\
\hline Sedentary, Solo, Indoors & & & -1.698 & -2.843 to -0.554 \\
\hline \multicolumn{5}{|l|}{ DIY/Gardening } \\
\hline Active, Social, Indoors & 1.061 & 0.175 to 1.947 & 1.232 & 0.118 to 2.347 \\
\hline Active Social, Outdoors & 1.268 & 0.026 to 2.509 & & \\
\hline Sedentary, Social, Outdoors & 1.748 & 0.995 to 2.501 & & \\
\hline \multicolumn{5}{|l|}{ Visiting/entertaining Friends/Family } \\
\hline Active, Social, Indoors & 1.138 & 0.319 to 1.957 & & \\
\hline Active, Social, Outdoors & 1.501 & 0.062 to 2.940 & & \\
\hline Sedentary, Social, Indoors & 0.787 & 0.050 to 1.524 & & \\
\hline \multicolumn{5}{|l|}{ Going to pub, club or restaurant } \\
\hline Sedentary, Social, Outdoors & 1.407 & 0.613 to 2.202 & & \\
\hline \multicolumn{5}{|c|}{ Volunteering, Caring for or Helping Someone } \\
\hline Active, Solo, Indoors & 2.164 & 1.458 to 2.870 & & \\
\hline Sedentary, Solo, Indoors & & & 2.730 & 0.280 to 2.647 \\
\hline Active, Social, Outdoors & 1.710 & 0.584 to 2.837 & 1.464 & 1.447 to 4.012 \\
\hline \multicolumn{5}{|l|}{ Mentally Active Activities } \\
\hline Active, Solo, Outdoors & & & 1.464 & 0.388 to 2.540 \\
\hline \multicolumn{5}{|c|}{ Concert, film or theatre, museum or gallery } \\
\hline Active, Social, Indoors & 1.829 & 0.855 to 2.803 & 1.888 & 0.628 to 3.148 \\
\hline Sedentary, Social, Indoors & 1.321 & 0.488 to 2.155 & & \\
\hline Sedentary, Social, Outdoors & 1.534 & 0.718 to 2.350 & & \\
\hline
\end{tabular}




\begin{tabular}{|lllll|}
\hline Predictors & Happiness & & Purpose \\
\hline Creative Hobby & & & & \\
\hline Active, Social, Indoors & 0.998 & 0.086 to 1.911 & 1.241 & 0.105 to 0.377 \\
\hline Active, Social, Outdoors & 1.491 & 0.423 to 2.560 & 1.212 & 0.010 to 2.415 \\
\hline Sedentary, Social, Indoors & 1.320 & 0.477 to 2.163 & 1.197 & 0.078 to 2.316 \\
\hline Resting & & & & -2.667 to -0.443 \\
\hline Sedentary, Solo, Indoors & -0.927 & -1.755 to -0.100 & -1.555 & -2.135 to -0.097 \\
\hline Sedentary, Solo, Outdoors & -1.096 & -1.809 to -0.384 & -1.116 & \\
\hline Travelling & & & & \\
\hline Active, Solo, Indoors & -1.047 & -2.045 to -0.049 & & 0.168 to 2.318 \\
\hline Sedentary, Solo, Indoors & -1.561 & -2.655 to -0.469 & & \\
\hline Sedentary, Solo, Outdoors & & & & \\
\hline Weekend/Weekday & & & & \\
\hline Weekend & 0.269 & 0.070 to 0.467 & \\
\hline Observations & 2,065 & & & \\
\hline Adjusted R-squared & 0.2335 & & & \\
\hline Model degrees of freedom & 65 & & \\
\hline
\end{tabular}

[ Table 4 here]

\section{Discussion}

The objective of this study was to investigate how the type (sedentary, active) and context (social and environmental) of older peoples' activities relate to momentary feelings of happiness or purpose to inform the design of interventions and policies. The finding that social (i.e. with other people) light sport/exercise was positively related to happiness, but that moderate-vigorous sport/exercise was not associated with either outcome, points to the potential challenges of promoting higher intensity activities in this age group (Downward and Dawson, 2016). For both outcomes, outdoor activities were associated with higher levels of happiness and sense of purpose. The association between outdoor activities and happiness has been noted previously (Finlay et al., 2015; Cabrita et al., 2017). However, the finding that outdoor activities were associated with greater momentary sense of purpose is new. This study also demonstrates that, although closely related, older people distinguish between the concepts of happiness and sense of purpose. The small overlap in the pattern of significant coefficients between the two outcomes illustrated this. Visiting friends and family, and going to a pub, club or restaurant were strongly associated with feelings of happiness but not purpose for example. Differences such as these suggest there is additional insight provided by investigating momentary sense of purpose (Dolan, 2014). The current analyses also show that less sedentary older adults on average experienced greater feelings of happiness compared with their more sedentary counterparts, which is in line with previous research (Lathia et al., 2017). However, a new finding is that less sedentary older adults also experienced even greater feelings of purpose during their activities. Overall the results suggest that policies and practices that encourage older adults to be less sedentary and spend more time in outdoor and social activities are likely to increase happiness and sense of purpose and could be leveraged to increase physical activity. For example, volunteering, even if solo, will enhance happiness and sense of purpose and if active, will also contribute to increased physical activity levels.

The study has two main limitations: first, the sample was not representative. For example, participants were more physically active (Sport England, 2019) and more highly-educated than UK adults of this age-group (OECD, 2020), likely due to the recruitment strategies and the need to exclude older people without smartphones. Second, the study was not designed to establish causal relationships; however momentary wellbeing was reported immediately after the activity had taken place, so causality is unlikely to be reversed. 
In conclusion, this research suggests that the context of leisure-time activities is important for older adults' feelings of both happiness and purpose, with social and outdoor activities being more likely to have the widest appeal. This should be considered when designing physical activity-increasing interventions and policy. There is value in future research measuring momentary sense of purpose as well as happiness in a larger and more representative sample of older people.

\section{Declarations}

\section{Competing interests}

The authors declare that they have no competing interests

\section{Availability of data and materials}

The datasets generated during the study are obtainable from the corresponding author on reasonable request

\section{Ethics approval and consent to participate}

The study received ethical approval from the Loughborough University Ethics (Human Participants) sub-committee on 24 Jan 2019

\section{Consent for publication}

Not applicable

\section{Funding}

No external funding

\section{Authors' contributions}

Karen Hancock: devised the surveys, conducted fieldwork, analysed data and drafted the manuscript as part of her PhD studies.

Prof. Paul Downward: provided technical advice on analysis and commented extensively on the manuscript.

Dr. Lauren Sherar: advised on data collection methods, processed raw accelerometer files and commented extensively on the manuscript.

All authors: conceived the idea for the study.

\section{Acknowledgements}

Not applicable

\section{References}

1. Actigraph. (2013) Actigraph wGT3X+/GT3 × 1 'Device Manual. Pensacola, Florida: Actigraph. Available at: https://www.actigraphcorp.com/support/downloads/ (Accessed: 2 February 2019).

2. Bangsbo J, et al. 'Copenhagen Consensus statement 2019: Physical activity and ageing'. Br J Sports Med. 2019;53(14):856-8. doi:10.1136/bjsports-2018-100451. 
3. Boulton ER, Horne M, Todd C. 'Multiple influences on participating in physical activity in older age: Developing a social ecological approach'. Health Expect. 2018;21(1):239-48. doi:10.1111/hex.12608.

4. Cabrita M, et al. 'An exploratory study on the impact of daily activities on the pleasure and physical activity of older adults'. European Review of Aging Physical Activity European Review of Aging Physical Activity. 2017;14(1):1-11. doi:10.1186/s11556016-0170-2.

5. Chang P-J, Wray L, Lin Y. 'Social Relationships, Health and Leisure in older adults'. Health Psychol. 2014;33(6):516-23. doi:10.1007/s10741-014-9462-7.

6. Copeland JL, Esliger DW. 'Accelerometer assessment of physical activity in active, healthy older adults'. Journal of Aging Physical Activity. 2009;17(1):17-30.

7. Dolan P. (2014) Happiness by Design. Allen Lane.

8. Downward P, Dawson P. 'Is it Pleasure or Health from Leisure that We Benefit from Most? An Analysis of Well-Being Alternatives and Implications for Policy', Social Indicators Research. Springer Netherlands. 2016;126(1):443-65. doi:10.1007/s11205-0150887-8.

9. Faul F, Erdfelder E, Lang A-G, Buchner A. 'G*Power 3: A flexible statistical power analysis program for the social, behavioral, and biomedical sciences'. Behav Res Methods. 2007;39:175-91.

10. Finlay J, et al. (2015) 'Therapeutic landscapes and wellbeing in later life: Impacts of blue and green spaces for older adults', Health and Place. Elsevier, 34, pp. 97-106. doi: 10.1016/j.healthplace.2015.05.001.

11. Galenkamp H, et al. 'Predictors of social leisure activities in older Europeans with and without multimorbidity'. European Journal of Ageing Springer Netherlands. 2016;13(2):129-43. doi:10.1007/s10433-016-0375-2.

12. Ipsos MORI. (2018) Taking Part Survey - 2017/18 Adult Questionnaire. London.

13. Kavčič T, Avsec A. 'A day in the lives of older adults: What makes them happy?'. Psiholoska Obzorja. 2018;27:51-60. doi:10.20419/2018.27.485.

14. Lam J, García-Román J. 'Solitary Day, Solitary Activities, and Associations With Well-Being Among Older Adults'. The Journals of Gerontology: Series B. 2019. doi:10.1093/geronb/gbz036.

15. Lathia N, et al. 'Happier people live more active lives: Using smartphones to link happiness and physical activity'. PLoS ONE. 2017;12(1):1-13. doi:10.1371/journal.pone.0160589.

16. Liu H, Lou VWQ. 'Developing a smartphone-based ecological momentary assessment protocol to collect biopsychosocial data with community-dwelling late-middle-aged and older adults'. Translational Behavioral Medicine. 2018;9(4):711-9. doi:10.1093/tbm/iby096.

17. Maher JP, Rebar AL, Dunton GF. 'Ecological momentary assessment is a feasible and valid methodological tool to measure older adults' physical activity and sedentary behavior'. Front Psychol. 2018;9(AUG):1-11. doi:10.3389/fpsyg.2018.01485.

18. OECD. (2020) Population with tertiary education (indicator), Data. doi: doi: 10.1787/0b8f90e9-en.

19. Oerlemans WGM, Bakker AB, Veenhoven R. 'Finding the key to happy aging: A day reconstruction study of happiness'. Journals of Gerontology - Series B Psychological Sciences Social Sciences. 2011;66 B(6):665-74. doi:10.1093/geronb/gbr040.

20. Office for National Statistics. (2015) Personal Well-being in the UK: Quality and Methodology Information. Available at: https://www.ons.gov.uk/peoplepopulationandcommunity/wellbeing/methodologies/personalwellbeingintheukqmi (Accessed: 2 February 2020).

21. Office for National Statistics. (2020) Annual Personal Wellbeing Estimates, National Statistics Datasets. Available at: https://www.ons.gov.uk/peoplepopulationandcommunity/wellbeing/datasets/headlineestimatesofpersonalwellbeing (Accessed: 10 April 2020).

22. Paolillo EW, et al. 'Smartphone-based ecological momentary assessment (EMA) of alcohol and cannabis use in older adults with and without HIV infection'. Addict Behav. 2018;83:102-8. doi:10.1016/j.addbeh.2017.10.016.

23. Patrick H, Williams GC. 'Self-determination theory: Its application to health behavior and complementarity with motivational interviewing'. International Journal of Behavioral Nutrition Physical Activity BioMed Central Ltd. 2012;9(1):18. doi:10.1186/14795868-9-18.

24. Pruitt LA, et al. 'Use of accelerometry to measure physical activity in older adults at risk for mobility disability'. Journal of Aging Physical Activity. 2008;16(4):416-34. doi:10.1123/japa.16.4.416. 
25. Public Health England. (2014) Everybody active, every day: An evidence-based approach to physical activity. London.

26. Ryan RM, Deci EL. 'On Happiness and Human Potentials: A Review of Research on Hedonic and Eudaimonic Well-Being'. Annu Rev Psychol. 2001;52(1):141-66. doi:10.1146/annurev.psych.52.1.141.

27. Sharifian N, Grühn D. 'The Differential Impact of Social Participation and Social Support on Psychological Well-Being: Evidence From the Wisconsin Longitudinal Study'. Int J Aging Hum Dev. 2019;88(2):107-26. doi:10.1177/0091415018757213.

28. Shiffman S, Stone AA, Hufford MR. (2008) 'Ecological momentary assessment.', Annual review of clinical psychology. United States, 4, pp. 1-32.

29. Sport England. (2019) Active Lives Survey data tables, Adult Survey. Available at: https://www.sportengland.org/know-youraudience/data/active-lives/active-lives-data-tables (Accessed: 27 February 2020).

30. StataCorp. (2018) 'Stata Statistical Software'. College Station; TX: StataCorp.

31. 'Experiential Wellbeing Data from the American Time Use Survey: $10.1007 / \mathrm{s} 11205-016-1532-x$

Stone AA, et al. (2018) 'Experiential Wellbeing Data from the American Time Use Survey: Comparisons with Other Methods and Analytic Illustrations with Age and Income', Social Indicators Research. Springer Netherlands, 136(1), 359-78. doi:10.1007/s11205-016-1532-x.

32. Tay L, Chan D, Diener E. 'The Metrics of Societal Happiness'. Soc Indic Res. 2014;117(2):577-600. doi:10.1007/s11205-0130356-1.

33. Verhaeghen P. (2013) The Elements of Cognitive Aging: Meta-Analyses of Age-Related Differences in Processing Speed and Their Consequences. Oxford University Press. doi: 10.1093/acprof:oso/9780195368697.001.0001.

34. Yamashita T, Bardo AR, Liu D. (2018) 'Experienced Subjective Well-Being During Physically Active and Passive Leisure-Time Activities Among Adults Aged 65 Years and Older', The Gerontologist, XX(XX), pp. 1-9. doi: 10.1093/geront/gny004.

\section{Supplementary Files}

This is a list of supplementary files associated with this preprint. Click to download.

- EMAPaperSTROBEchecklistpopulated.doc 